\title{
Subtle and negligible effects of rainfall on estuarine infauna: evidence from three years of event-driven sampling
}

\author{
Richard B. Ford ${ }^{1, *}$, Marti J. Anderson ${ }^{2}$, Shane Kelly ${ }^{3}$ \\ ${ }^{1}$ Leigh Marine Laboratory, University of Auckland, Private Bag 92019, Auckland, New Zealand \\ ${ }^{2}$ Department of Statistics, University of Auckland, Private Bag 92019, Auckland, New Zealand \\ ${ }^{3}$ Auckland Regional Council, Private Bag 92012, Auckland, New Zealand
}

\begin{abstract}
Events of heavy rainfall can impact benthic fauna in estuaries. The occurrence of heavy rainfall is predicted to increase in many places due to climatic warming. It is therefore important to know the likely impact of events of heavy rainfall, both now and in the future, particularly as the discharge of some contaminants, such as sediments from large-scale urban developments, is correlated with such events. We tested for evidence of any impacts of rainfall on the structure of assemblages over a period of $3 \mathrm{yr}$, using event-driven sampling of macrofaunal soft-sediment communities across 5 estuaries in the Auckland region of New Zealand. Changes in assemblage structure that were correlated with gradients in rainfall were detected at only 2 of 50 sites sampled. These site-specific impacts were detected in only one estuary and did not coincide with the largest amount of rainfall measured in the region over that period. Impacts were characterised by a short-term increase in the number of taxa, which probably resulted from deposition of fauna transported with bedload eroded from upstream sites due to increased flow rates. This contrasts with results from previous studies, which reported catastrophic decreases in biodiversity or abundance with storm events. Our work provides a realistic baseline against which potential future impacts of rainfall associated with land development can be tested. We suggest long-term monitoring studies that incorporate measurements of relevant physical variables, including rainfall, are needed in order to more effectively assess significant changes in naturally temporally variable communities.
\end{abstract}

KEY WORDS: Soft-sediment communities · Climate change - Environmental impacts · Monitoring · Macrofauna $\cdot$ New Zealand

\section{INTRODUCTION}

Increasing intensity and variability of storms and events of heavy rainfall are prominent features of climate change predictions for many parts of the world (Hicks 1990, Whetton et al. 1996). Increasing intensity of rainfall is often correlated with increased occurrences of wind-driven waves, larger pulses of freshwater inflow and increased sediment deposition into estuaries and coastal systems (Griffiths 1981, Hicks 1990, Airoldi 2003). The potential impacts of increasing rainfall intensity on estuaries may include changes to sedi- ment stability, nutrient loads, biotic community structure, post-settlement movement and trophodynamics (Committo et al. 1995, Thrush et al. 1996, Kennish 2002). In addition, increased sediment input into coastal ecosystems, generally caused by land clearance, is recognized as a major marine contaminant (GESAMP 1990). It is therefore important to understand the potential impact of events of heavy rainfall on estuarine and coastal communities, both now and in the future under expected climate-change predictions.

Evidence for storm-driven changes in macrobenthic assemblages is based primarily on observations of 
changes in faunal composition that are correlated with either single storm events or seasonal changes in the frequencies of storms (e.g. Hall 1994). Previous studies also report changes in assemblages attributable to freshwater pulses (Hoese 1960, Tettelbach et al. 1985) sedimentation events (Peterson 1985) or wind-driven waves (Thrush et al. 1996, Norkko et al. 2002). Experimental work has shown that deposition of terrestrial sediments, mimicking storm-induced depositions, can cause decreased diversity in estuaries (Norkko et al. 2002, Lohrer et al. 2004). Conversely, Dobbs \& Vozarik (1983) reported no significant effect of a single storm event on the macrobenthos at a shallow subtidal study site, although the authors postulated that effects may have been more pronounced at more exposed sites.

Estuaries are often shallow and can be characterized by mixing of fresh and saline waters and by high rates of sediment deposition (Dyer 1986). Although heavy rainfall events are likely to show strong impacts in estuarine environments, it is not known whether periodic ongoing natural events of relatively heavy rainfall result in detectable effects on assemblage structure in estuaries.

In the New Zealand context, soil erosion is seen as a major problem (Griffiths \& Glasby 1985). Griffiths (1981) suggested that rainfall was by far the most important factor influencing sediment yield in parts of New Zealand. Indeed, rapid uplift, geological youth, high annual rainfall and deforestation have combined to make rates of erosion in New Zealand among the highest known (Griffiths \& Glasby 1985). Auckland is surrounded by multiple estuaries and there has been growing concern about the ecological impacts of sedimentation on benthic macrofauna in these habitats (Norrko et al. 2002, Hewitt et al. 2003, Lohrer et al. 2004), due to urbanisation of catchments in the region. The Auckland Regional Council has therefore implemented a long-term estuarine macrobenthic monitoring programme. Sampling of physical and biological attributes of multiple estuaries across the region is carried out several times each year.

It is anticipated that, as urban development proceeds in surrounding catchments, estuaries will receive greater sediment deposition and, furthermore, that such deposition will be especially acute after periods of heavy rainfall. The timing of sampling in the monitoring programme is therefore structured with respect to rainfall events (i.e. after relatively heavy rainfall and after relatively dry periods), thus providing an opportunity to assess the potential impacts on macrobenthic communities of rainfall events of varying magnitudes. The purpose of this study was to examine data from $3 \mathrm{yr}$ of event-driven sampling in order to test the hypothesis that there will be detectable and characterisable changes in assemblage structure in response to rainfall events monitored over time across multiple estuaries of the Auckland region.

\section{METHODS}

Study sites. We used data from an ongoing monitoring programme which has quantified the abundance and diversity of intertidal sediment macrofaunal communities from each of 5 estuaries, 12 times over a period of nearly $3 \mathrm{yr}$, from August 2002 to April 2005. These estuaries occur within the greater Auckland region in northern New Zealand, near the margins of the greater metropolitan area. They are separated by $<50 \mathrm{~km}$, and have similar aspects, opening towards the east or northeast into the Hauraki Gulf (Fig. 1).

Within each estuary, 10 sites (covering distances of 1 to $3 \mathrm{~km}$ from the mouth of each estuary) were established

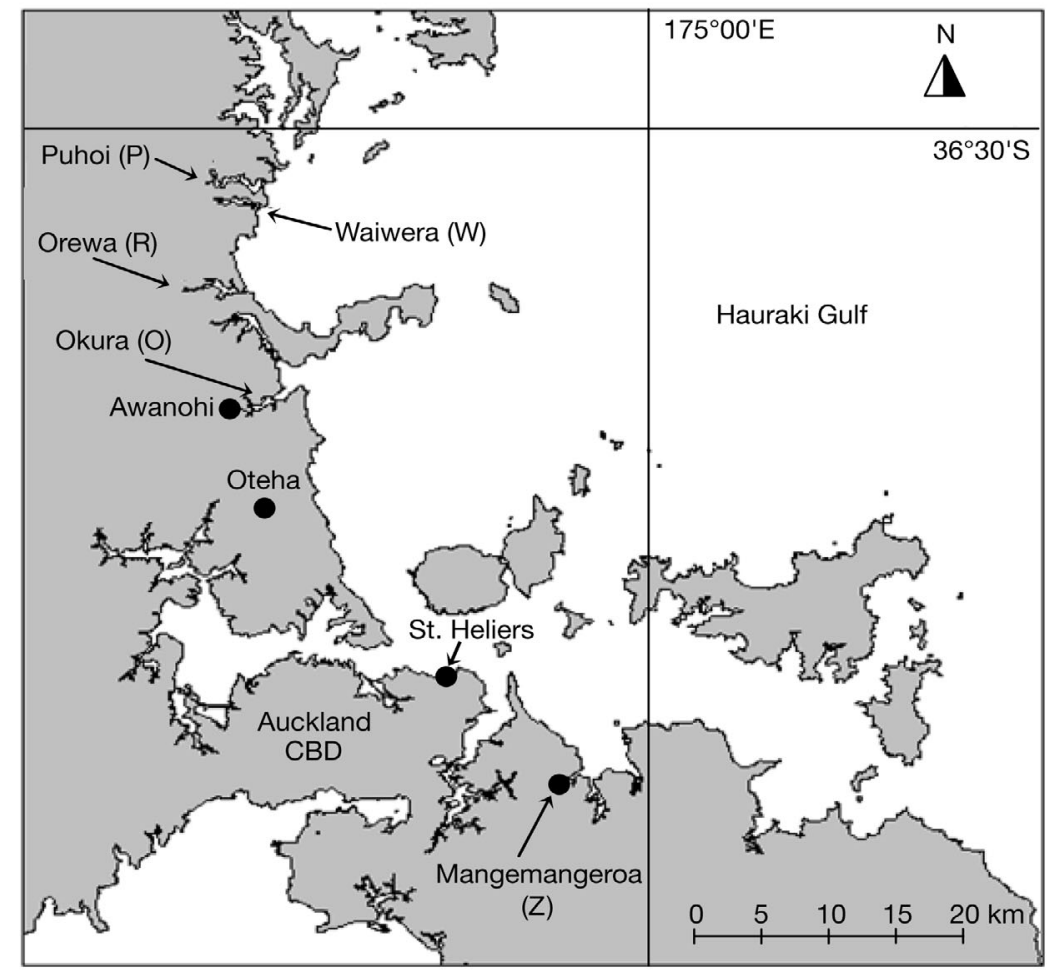

Fig. 1. Map of the East Coast of the Auckland Region showing all 5 estuaries sampled. Abbreviations used for estuaries are shown in brackets after each name. CBD: central business district 
within mid-intertidal unvegetated sediments. Sites covered a range of sediment and community types, as described by Anderson et al. (2004) and Ford \& Anderson (2005). Each site was chosen to be a homogeneous sandor mudflat $50 \mathrm{~m}$ long (parallel with the direction of water flow) and $25 \mathrm{~m}$ wide. The sites covered the length of each estuary and spanned a wide range of sediment textures. Each site is labelled with 2 letters. The first indicates the estuary: Puhoi (P), Waiwera (W), Orewa (R), Okura (O) or Mangemangeroa $(\mathrm{Z})$; the second labels sequentially sites from A to $\mathrm{J}$, with site $\mathrm{A}$ at the seaward end and site $J$ at the landward end.

Sampling design. Of greatest interest to the Auckland Regional Council is the determination of effects on estuarine ecology of increased sediment loads associated with urban earthworks. Impacts are expected to be most apparent after periods of heavy rainfall. Therefore, sampling for ongoing monitoring contracted by the council was designed to be event-driven. In each of 2 seasons in every year, sampling was done after heavy rainfall and also after a relatively dry period. Seasons were defined as 2 discrete 3 mo blocks: August to October (winter/spring) and February to April (late summer). These seasons were chosen because of their contrasting patterns of rainfall and potential construction activity. Although similar mean amounts of rain $\left(\sim 80\right.$ to $\left.150 \mathrm{~mm} \mathrm{mo}^{-1}\right)$ fall in both seasons, events tend to be small and frequent in winter/spring, but are more variable, larger and more infrequent in summer (Hessell 1988). In addition, the majority of large-scale earthworks in the region occur in summer.

Examination of a $17 \mathrm{yr}$ data set from the Leigh Marine Laboratory meteorological records $(\sim 25 \mathrm{~km}$ north of Puhoi Estuary) showed that a rainfall event of at least $15 \mathrm{~mm}$ could be reliably expected to occur at least twice in every season. In addition, Norkko et al. (2002) showed that effects of experimental sediment deposition $(>4 \mathrm{~cm})$ were detectable in benthic assemblages in the Okura estuary after a period of $7 \mathrm{~d}$. Thus, within each season, event-driven sampling was done twice: (1) 7 to10 d after a rainfall event, defined as $\geq 15 \mathrm{~mm}$ of rainfall in a $24 \mathrm{~h}$ period ('Rain') and (2) when such a rainfall event has not occurred in $\geq 10 \mathrm{~d}$ ('Dry'). The level of rainfall that triggered sampling was gauged from either the St. Heliers or Oteha weather stations, which are central to all estuaries, as available (http://homepages.paradise.net.nz/tmcgavin/current_ nzweather.html and http://maps.arc.govt.nz/website/ maps/map_hydrotel.htm, respectively). All 5 estuaries were sampled within a maximum of $7 \mathrm{~d}$ from the start of sampling at each time. This monitoring programme is ongoing.

Data from 12 sampling events spread across $3 \mathrm{yr}$ (2002-2003, 2003-2004 and 2004-2005) were inclu- ded in the analyses presented here. Although all estuaries were sampled at each time point, and a single 'trigger' was used to identify a 'rainfall event', there was considerable variation in actual rainfall at different estuaries for a given time of sampling and across different rainfall events.

Our aim was to examine and characterise the relationship, if any, between rainfall and faunal assemblage structure, and thus further, more detailed quantitative information on rainfall events was obtained subsequently using data from 3 rainfall gauges: Mangemangeroa, Orewa, and Awanohi (Okura) (http://maps. arc.govtnz/website/maps/map_hydrotel.htm), which were not available when the monitoring was established. For each time of sampling and at each estuary, the total amount of rain (in $\mathrm{mm}$ ) was calculated over a period of (1) $1 \mathrm{wk}$ and (2) 1 mo prior to sampling the fauna. Although daily rainfall data were generally available, this integrative approach was adopted as appropriate for the temporal scale of the biological sampling. Where rainfall data were missing for a particular estuary, values were generated using a rain gauge less than $15 \mathrm{~km}$ distant (including Beachlands, Anakaena and Oteha, available from the same URL address) and within an area having the same average annual rainfall to within $\pm 100 \mathrm{~mm}$ (Hessell 1988). For example, for Puhoi and Waiwera estuaries, the amount of rainfall was calculated from the gauge at the nearby Orewa estuary for all times. Comparisons of rain gauges less than $15 \mathrm{~km}$ apart within the region showed correlations of 0.75 or 0.94 when weekly or monthly values, respectively, were compared.

Macrofaunal sampling. Macrofaunal samples on each sampling occasion consisted of 6 randomly positioned cores within each site. Cores were cylindrical in shape, measuring $13 \mathrm{~cm}$ in diameter and $15 \mathrm{~cm}$ deep. Each core was sieved in the field using $0.5 \mathrm{~mm}$ mesh. Material retained on the sieve was brought back to the laboratory for sorting and taxonomic identification. Material retained was preserved in $70 \%$ isopropyl alcohol with $0.01 \%$ Rose Bengal. All organisms were identified to the lowest practical level of taxonomic resolution, resulting in a total of 84 taxa used in subsequent analyses.

Environmental measures. Environmental measures were also collected at each site. These consisted of ambient sediment texture, a measure of bed-height movement and measures of trapped sediment at each site. Ambient sediments were collected in August 2002 using a $38 \mathrm{~mm}$ diameter corer to a depth of $15 \mathrm{~cm}$ alongside each macrofaunal core. Subsequently, a core measuring $20 \mathrm{~mm}$ diameter $\times 20 \mathrm{~mm}$ deep was used. Sediment materials from the 6 cores from each site were combined before processing. All sediments were pre-treated using $10 \%$ hydrogen peroxide for $24 \mathrm{~h}$ to 
dissolve organics and then Calgon ${ }^{\mathrm{TM}}$ was used to disperse the sediments. Wet sieving was then used to determine the proportional weights of sediments in different size fractions: mud $(<0.063 \mathrm{~mm})$, very fine sand $(0.063$ to $0.125 \mathrm{~mm})$, fine sand ( 0.125 to $0.25 \mathrm{~mm}$ ), medium sand $(0.25$ to $0.5 \mathrm{~mm})$ and coarse sand or larger ( $>0.5 \mathrm{~mm})$.

Measures of bed-height changes and the relative rates of sediment accumulating in sediment traps were also collected at each site. These measures were collected monthly where possible throughout the $3 \mathrm{yr}$. Bed-height change was gauged relative to the top of a stake buried at each site, exclusive of any scour at the base of the stake, and was expressed as a change in $\mathrm{cm} \mathrm{d}^{-1}$. Trapped sediments were collected at each site from sediment traps that were $50 \mathrm{~cm}$ long, with openings $3.7 \mathrm{~cm}$ in diameter positioned 20 to $25 \mathrm{~cm}$ above the bed. Accumulations of sediments in traps were calculated as rates in $\mathrm{g} \mathrm{cm}^{-2} \mathrm{~d}^{-1}$. Grain-size fractions of sediment deposited in traps were also determined using the same methodology as for ambient sediments. Considerable caution is needed in interpreting data obtained from these traps. First, accumulation of sediment in traps does not necessarily correlate with deposition of sediments on the bed at that site, due to potential resuspension and differences in height. Second, at some sites and times of sampling (see Results), sediments very nearly filled the traps (yielding an aspect ratio <10), in which case, substantial resuspension would be expected and measures of the amount of trapped sediment should be considered conservative. Nevertheless, the traps used do provide a proxy relative measure to indicate sediment availability in the water column across the sites and also through time at a given site. For additional details concerning these methods, see Anderson et al. (2004).

Statistical analyses. Of central interest was the relationship between the entire set of multi-species assemblage data and the quantitative variable of rainfall. It was first necessary to determine spatial scale at which the effect of rainfall should be examined, viz. the regional, estuary or individual site levels. Rainfall is naturally intrinsically confounded with time (with different amounts of rain measured prior to each sampling time). Thus, the appropriate spatial scale to examine rainfall effects was determined by first analysing the full multivariate dataset in response to the general experimental design of: Estuary (5 levels, fixed), Site (10 levels, nested within Estuary) and Time (12 levels, fixed). A significant interaction between either Time and Site or Time and Estuary would indicate that rainfall should be examined at the level of individual sites or individual estuaries, respectively.

Multivariate normality was not a reasonable assumption for these data, as they contained many zero values and abundance frequencies were heavily rightskewed. Thus, a permutational multivariate analysis of variance (PERMANOVA) was done based on BrayCurtis dissimilarities of $\ln (y+1)$-transformed abundances (Anderson 2001, McArdle \& Anderson 2001). This approach allows the analysis to be based on any dissimilarity measure of choice, and provides a partitioning of the multivariate data in response to any ANOVA experimental design. We obtained p-values using 4999 permutations of appropriate units (Anderson \& ter Braak 2003). This analysis was very time-consuming, given the large total number of sample units $(n=3600)$. A random subset of 4999 permutations is sufficient, however, to allow inferences at a significance level of 0.05 (Manly 1997).

The analysis demonstrated a significant Time $\times$ Site (Estuary) interaction, indicating that rainfall effects should be examined separately at the level of each individual site (see Results). Therefore, the next step was to examine the relationship between the multispecies abundance data and the quantitative variable of rainfall prior to sampling (either weekly or monthly). This was done separately for assemblages at each site, using a distance-based multivariate multiple regression (McArdle \& Anderson 2001). There were 50 sites, however, so some form of control for the familywise type I error rate across all tests was warranted. The Bonferroni approach is known to be quite conservative in the face of correlation among tests, which was expected to occur to some extent among sites.

Familywise error rates were controlled using the method described by Manly et al. (1986), Westfall \& Young (1993) and Manly (1997). In essence, separate permutations were done in the usual manner for each separate test to obtain permutation distributions. For the observed value of the test statistic (say, $F_{\text {obs }}$ ), a $\mathrm{p}$-value is calculated as the number of values of the test statistic under permutation $\left(F^{*}\right)$ that equal or exceed the observed value (plus one), divided by the number of permutations (plus one). The 'plus one' in each case ensures that the observed value itself is included as a member of the permutation distribution. Note that every test statistic obtained under permutation also has an associated p-value which can be calculated in this way to identify its location empirically within that permutation distribution. For a given permutation, the minimum p-value across all tests (in our case, sites) can therefore be determined. The empirical distribution of these minimum p-values is then used to identify a corrected level at which a given familywise error rate across all tests can be controlled. That is, suppose $\alpha=$ 0.05 , then the 0.05 -quantile of the distribution of minimum $p$-values is the new $\alpha^{\prime}$ that should be used for each separate test to maintain the familywise error rate at $\alpha$. A custom computer program was written in 
FORTRAN to produce critical values of the test statistic under permutation for multiple tests using this method, with the kernel of the program being the multivariate distance-based multiple regression (McArdle \& Anderson 2001) done at each site.

These and all subsequent multivariate analyses were done on the basis of Bray-Curtis dissimilarities of $\log (y+1)$-transformed abundances after summing abundance information from the 6 individual cores at the site level. Analyses were done using the multivariate $F$ statistic and 9999 permutations for the relationship between ecological assemblage data and cumulative measures of rainfall (1) during the previous week and, separately, (2) during the previous month.

Patterns in multivariate assemblages through time at sites where a significant relationship with rainfall was found were investigated in greater detail using nonmetric multi-dimensional scaling, with superimposed circles whose diameters indicated rainfall values. Hierarchical agglomerative cluster analysis was then used along with the SIMPROF algorithm available in PRIMER v.6 (Clarke \& Gorley 2006) to determine significant cluster groupings of these assemblages. To characterise the nature of the relationship between fauna and rainfall, where significant, a canonical analysis of principal coordinates (CAP; Anderson \& Willis 2003) was used. Individual taxa having a correlation of $|r|>0.4$ with the canonical axis were examined in further detail, along with the total number of taxa and also the total abundance of all taxa, using scatter plots.

In addition, for those sites where a significant rainfall effect was detected, the potential relationship between rainfall and the environmental variables was analysed using analysis of covariance, with rainfall as the continuous variable, and site as the factor. This was done to determine the extent to which marked biological responses to rainfall may be linked to concomitant changes in measured environmental parameters. The interaction between rainfall and site was also fitted into the ANCOVA models as there was no reason to assume constant slopes among sites for these relationships. Each environmental variable fulfilled the required assumptions (normality and homogeneity) and these analyses were done using the computer program R (R Development Core Team 2005).

\section{RESULTS}

A fairly large range in rainfall was recorded across the 12 sampling times and 5 estuaries, from 0 to $75 \mathrm{~mm}$ for the week prior to sampling, and 3 to $303 \mathrm{~mm}$ for the month prior to sampling. The 2 largest monthly rainfalls (303 $\mathrm{mm}$ at Okura and $275 \mathrm{~mm}$ at Orewa) were in the highest $2 \%$ of historical monthly rainfall totals for the area (gauged from 26 yr of rainfall data from Orewa Estuary, http://maps.arc.govt.nz/website/maps/ map_hydrotel.htm). This suggests that rainfall of this scale per calendar month could be expected approximately once every $4 \mathrm{yr}$. The 25th, 50th and 75th percentiles for the weekly data were 11,18 and $37 \mathrm{~mm}$, respectively, while those for the monthly data were 63 , 108 and $166 \mathrm{~mm}$.

Eighty-four taxa and 144663 ind. were identified and enumerated. The fauna were numerically dominated by 6 taxa, which made up more than $55 \%$ of all individuals. In decreasing order of abundance, these were barnacles $(12.7 \%)$, the venerid bivalve Austrovenus stutchburyi (12.5\%), the nuculid bivalve Nucula hartvigiana $(8.0 \%)$, the corophid amphipod Paracorophium sp. (7.9\%), the mesodesmatid bivalve Paphies australis $(7.1 \%)$ and the spionid polychaete Prionospio sp. $(6.9 \%)$. There was a significant interaction in the multivariate data between the factors of Time and Site (Estuary) (Table 1), indicating that temporal changes in assemblage structure, whether triggered by rainfall or otherwise, needs to be investigated at the level of individual sites.

There was no statistically significant relationship between assemblages and rainfall measured for the previous week when the tests were adjusted for multiple comparisons (Fig. 2a). Although 3 sites ( $\mathrm{PH}$, WD and RF) exceeded the per-comparison error rate of $\alpha=0.05$ (with values of $0.046,0.010$ and 0.015 , respectively), the familywise adjusted significance level of $\alpha^{\prime}=0.0011$ was not approached. However, there were 2 sites where the assemblages demonstrated extremely strong relationships with rainfall measured for the month prior to sampling that equalled or very nearly equalled this adjusted significance level. These were Site A and Site D in the estuary at Orewa (see Sites RA and RD in Fig. 2b), which had permutation p-values of 0.0013 and 0.0011 , respectively. Data from these 2 sites were therefore investigated in greater detail to characterise the nature of this relationship.

Table 1. PERMANOVA based on Bray-Curtis dissimilarities, calculated on $\ln (y+1)$-transformed abundances, examining effects of spatial and temporal factors on estuarine intertidal assemblages at the level of individual cores (88 taxa, 4999 permutations)

\begin{tabular}{|lrrrc|}
\hline Source & df & MS & $F$ & $p$ \\
\hline Time (T) & 11 & 23360 & 6.044 & 0.0002 \\
Estuary (E) & 4 & 148646 & 2.277 & 0.0028 \\
T $\times$ E & 44 & 17022 & 4.404 & 0.0002 \\
Site (E) & 45 & 65276 & 50.674 & 0.0002 \\
T $\times$ Site (E) & 495 & 3865 & 3.000 & 0.0002 \\
Residual & 3000 & 1288 & & \\
Total & 3599 & & & \\
\hline
\end{tabular}




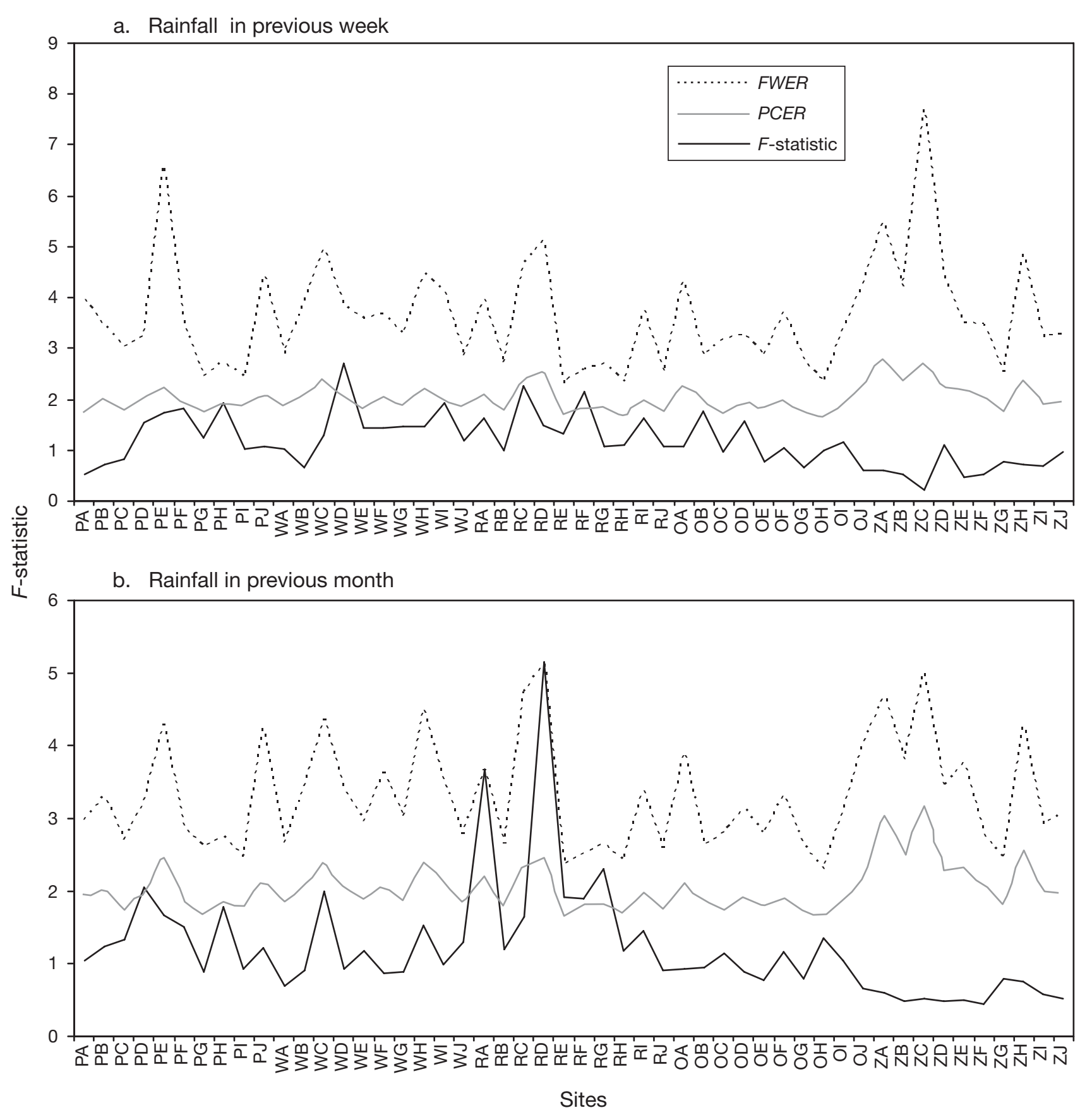

Fig. 2. F-statistic at each of 50 sites for the multivariate regression of biological data (88 taxa) versus rainfall (in mm) in (a) the preceding week and (b) the preceding month. Also shown are the critical values using either a per-comparison error rate (PCER, $\alpha=0.05$ ) or a familywise error rate (FWER, $\alpha^{\prime}=0.0011$ )

The non-metric MDS plot of assemblages from these 2 sites (Fig. 3) indicated changes in community structure when moving from left to right in the ordination diagram. Assemblages sampled after small amounts of rainfall in the previous month (Times 9 to 12) occur at the far left of the plot, those sampled after intermediate to large amounts of rainfall (Times 1 to 4,7 and 8) occur in the middle of the plot and assemblages sampled after large amounts of rainfall (Times 5 and 6) generally occur to the right. The consistent response to rainfall observed at these 2 sites was reinforced by patterns seen in the cluster analysis, with similarity profiles indicating significant structural differences among groups of assemblages as shown by partitions on the 


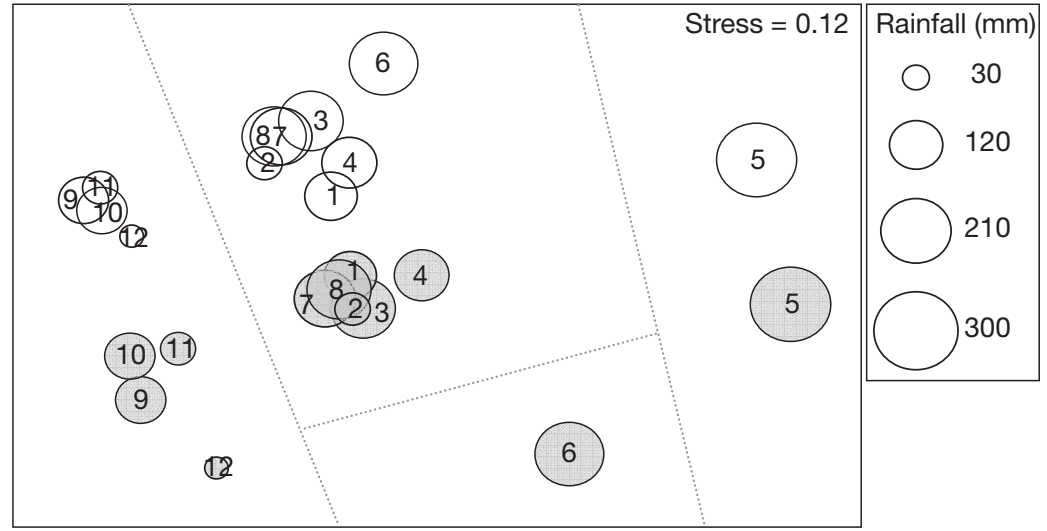

Fig. 3. Non-metric multi-dimensional scaling (MDS) ordination of assemblages based on Bray-Curtis dissimilarities of $\ln (y+1)$-transformed abundances for 88 taxa at Site A (O) and Site D (O) at Orewa. The size of each bubble indicates the relative amount of rainfall in the previous month and labels (from 1 to 12) indicate the chronological time of sampling. Lines across the plot indicate significant breaks in the hierarchical agglomerative cluster analysis as determined using the similarity profile (SIMPROF) analysis

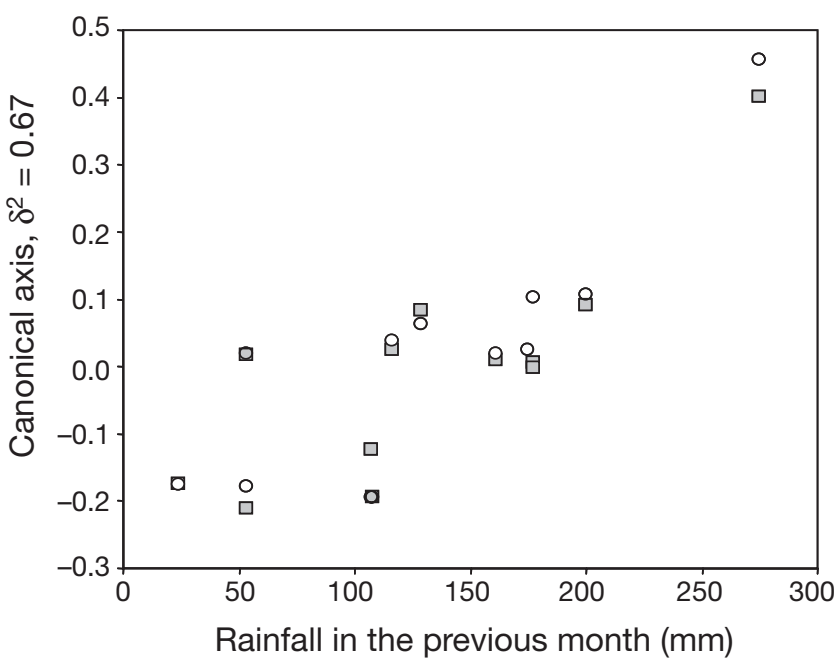

Fig. 4. Canonical analysis of principal coordinates (CAP) of the relationship between rainfall in the previous month (in $\mathrm{mm}$ ) and the assemblages (based on Bray-Curtis dissimilarities of $\ln (y+1)$-transformed abundances) at Site A ( $\square$ ) and Site D (O) in Orewa estuary

MDS plot (Fig. 3). In particular, assemblages observed after the heaviest rainfall (Time 5) were clearly distinguishable from those sampled previously. These effects were short-lived, however, with assemblages at Times 7 and 8 being structurally indistinguishable from those observed at Times 1 to 4 at both of the sites.

As the direction of change in these assemblages was similar at both sites, a single canonical analysis of principal coordinates versus rainfall (in the previous month) was warranted (Fig. 4). Although the canonical correlation with rainfall was fairly strong $(\delta=0.82)$, this was driven largely by the marked differences between assemblages at both sites after the heaviest rainfall (200 and $275 \mathrm{~mm}$ in the previous month) and assemblages seen at other times (Fig. 4). Several individual species are indicators of this change in assemblage structure. First, there were some species that showed a marked increase in occurrence and/or abundance after heavy rainfall, such as the anemone Anthopleura spp., the scavenging predatory whelk Cominella glandiformis, the deposit-feeding capitellid polychaete Heteromastus sp., the bivalve Nucula hartvigiana, the spionid polychaete Aonides sp., the limpet Notoacmea sp. and nemertean worms (Fig. 5). In contrast, insects and some motile crustaceans showed decreased abundance with increased rainfall, such as Waitangi sp. and Cirolana sp., although these taxa were highly variable. In general, the number of taxa at these sites increased markedly at the time when the highest rainfall was recorded (from $~ 10-15$ to around 25-30 taxa), although the total number of individuals showed no clear trends (Fig. 5).

Many of the environmental variables recorded showed no significant relationship with rainfall at either of these sites (Table 2). There was a significant relationship between rainfall and the average rate of sediment accumulated in traps, although, interestingly, the pattern that occurred was the reverse of what might be expected. There was a decrease in this variable with increases in rainfall (Fig. 6). However, the data from traps at Site RA, and analyses based on them (Table 2, Fig. 6) should be viewed with caution, as this was one of the 3 sites out of 50 where sediment traps were overfilled (with an average aspect ratio of $\sim 4$ ), so that resuspension was likely affecting the amount and texture of collected sediments. Despite this issue, there was a significant increase in the percentage of fine sediment in the traps across both sites with increasing rainfall (Table 2, Fig. 6), and a positive relationship between rainfall and the average rate of mud accumulated in traps (Table 2, Fig. 6).

\section{DISCUSSION}

The effects of rainfall on community structure were subtle and were not widespread throughout the Auckland region. A significant relationship between rainfall and community structure was observed at only 2 sites (RA and RD) in the Orewa estuary out of a possible 50 sites in 5 estuaries (Fig. 2). Effects were most obvious 

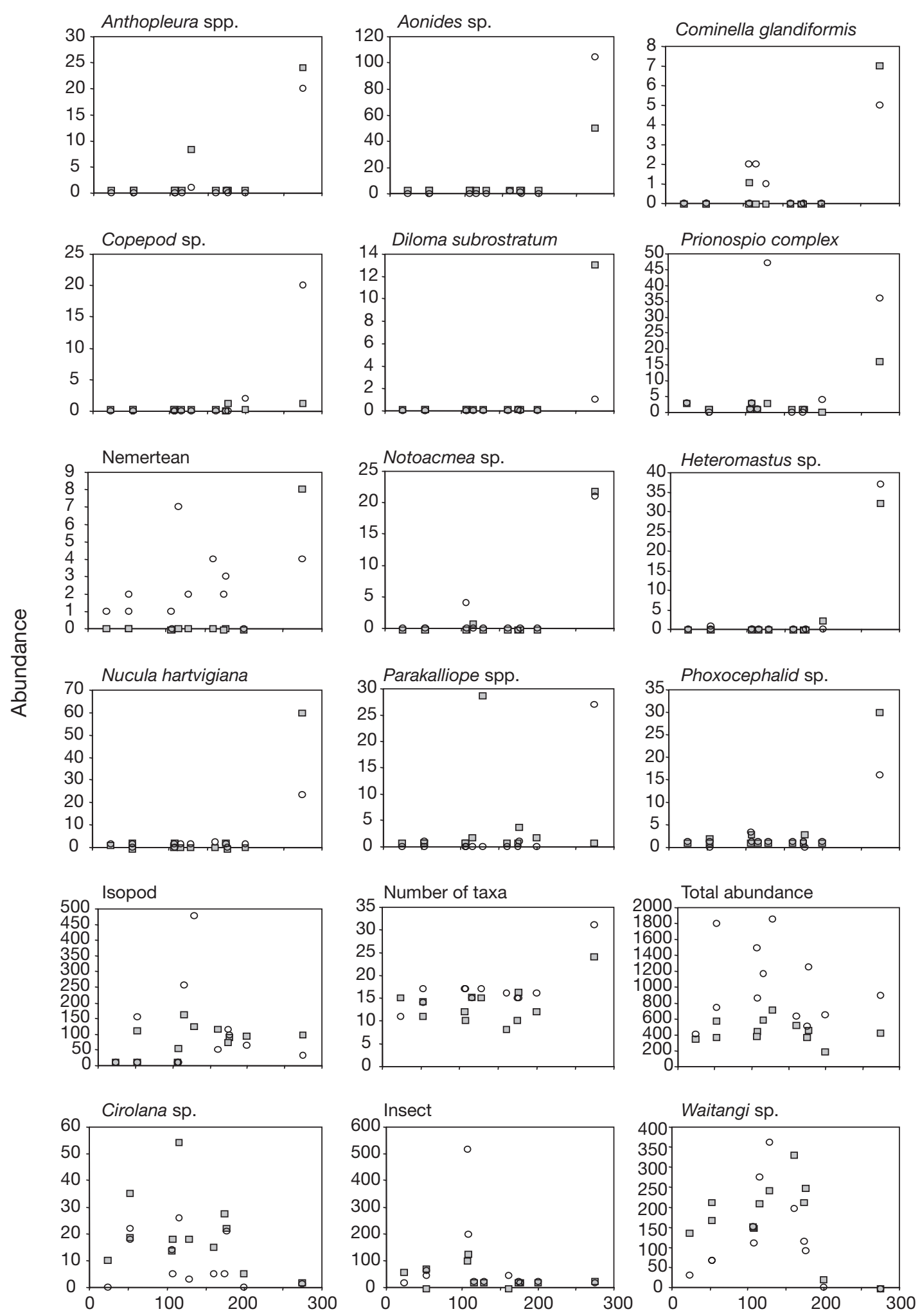

Rainfall in previous month $(\mathrm{mm})$

Fig. 5. Scatterplots of the abundances (per site $=6$ cores summed) of certain individual taxa (having a correlation of $|r|>0.4$ with the CAP axis in Fig. 4) and of the total number of taxa and the total number of individuals versus rainfall in the previous month (in $\mathrm{mm}$ ) at Site $\mathrm{A}(\square)$ and Site D (O) in Orewa estuary 
Table 2. Analyses of covariance of environmental variables from Sites A and D in Orewa only, examining the relationship with rainfall (in $\mathrm{mm}$ ) in the preceding month ( $\mathrm{n}=$ sample size). $\mathrm{BH}$ : bed height change; Trap: average rate of sediment accumulation in traps; Trap \% fine: percentage of mud $(<63 \mu \mathrm{m})$ in trapped sediment; Trap mud: average rate of mud accumulated in traps. The remaining 5 variables are proportions of ambient sediments of different grain sizes, as defined in the text. Values in bold indicate statistically significant effects

\begin{tabular}{|lcccrrrrr|}
\hline \multirow{2}{*}{ Variable } & $\mathrm{n}$ & \multicolumn{2}{c}{ Rain (R) } & \multicolumn{2}{c}{ Site (S) } & \multicolumn{2}{c|}{$\mathrm{R} \times \mathrm{S}$} \\
& & $F$ & $\mathrm{p}$ & \multicolumn{1}{c}{$F$} & $\mathrm{p}$ & $F$ & $\mathrm{p}$ \\
\hline $\mathrm{BH}$ & 22 & 0.249 & 0.624 & 1.656 & 0.215 & 0.010 & 0.923 \\
Trap & 23 & 5.476 & $\mathbf{0 . 0 3 0}$ & 37.817 & $\mathbf{< 0 . 0 0 1}$ & 4.004 & 0.060 \\
Trap \% fine & 23 & 9.583 & $\mathbf{0 . 0 0 6}$ & 82.063 & $\mathbf{< 0 . 0 0 1}$ & 0.899 & 0.355 \\
Trap mud & 23 & 4.796 & $\mathbf{0 . 0 4 1}$ & 8.800 & $\mathbf{0 . 0 0 8}$ & 0.998 & 0.330 \\
Mud & 17 & 0.011 & 0.917 & 9.107 & $\mathbf{0 . 0 0 9}$ & 0.600 & 0.451 \\
Very fine sand & 17 & 0.411 & 0.532 & 0.643 & 0.436 & 0.000 & 0.988 \\
Fine sand & 17 & 0.012 & 0.914 & 0.017 & 0.899 & 0.303 & 0.591 \\
Medium sand & 17 & 0.069 & 0.796 & 7.000 & $\mathbf{0 . 0 1 9}$ & 0.001 & 0.983 \\
Coarse sand & 17 & 1.267 & 0.279 & 0.260 & 0.618 & 0.079 & 0.783 \\
\hline
\end{tabular}

(a)

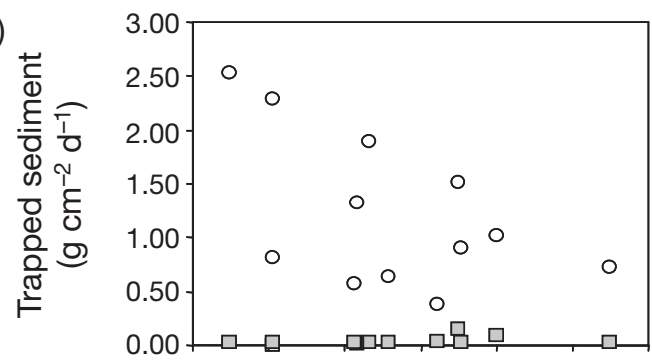

(b)

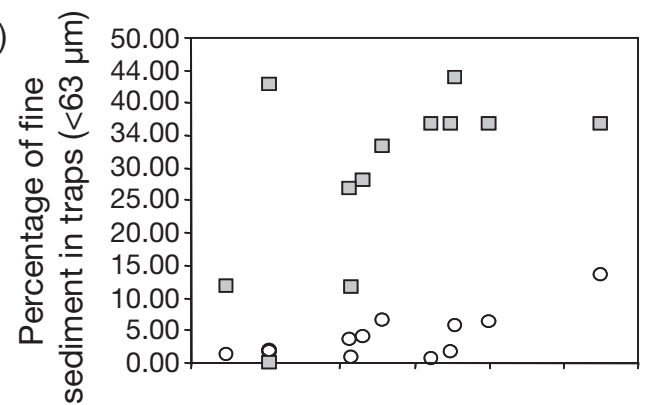

(c)

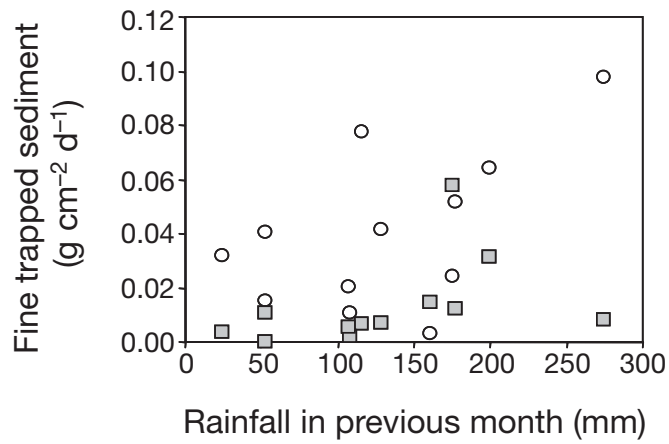

Fig. 6. Scatterplots showing the relationships between each of: (a) the average rate of sediment accumulation in traps, (b) the percentage of fine sediment or mud $(<63 \mu \mathrm{m})$ in traps, (c) the average amount of fine sediment $(<63 \mu \mathrm{m})$ accumulated in traps versus rainfall in the previous month (in $\mathrm{mm}$ ) at Site A ( $\square$ ) and Site D (O) in Orewa estuary when rainfall exceeded $200 \mathrm{~mm}$ in the month prior to sampling. In contrast, the highest rainfall recorded in the month preceding any sampling $(303 \mathrm{~mm}$ at Okura, almost a quarter of the annual average rainfall) was not correlated with any significant changes in community structure. Thus, the effects of rainfall are clearly site-specific. The amount of rain recorded in this study (with a maximum of $90 \mathrm{~mm}$ over a period of $1 \mathrm{wk}$ ) were below levels that have caused catastrophic effects reported in other studies (e.g. $210 \mathrm{~mm}$ over $2 \mathrm{~d}$, Tettelbach et al. 1985). Our study has painted a realistic picture, however, of the more subtle impacts, or rather more generally, a lack of any impacts, of smaller and more frequent rainfall events.

The effects of rainfall were also short-lived. Communities were most affected by rainfall at Sites RA and RD at Time 5 (August 2002). By Time 6 (45 d later in October 2003) communities had already reverted to being more similar to those observed at other sampling times, when smaller amounts of rainfall had been recorded (Figs. $3 \& 4$ ). This contrasts with studies where sediments were experimentally deposited onto benthic communities, in which recovery could take over a year (Hewitt et al. 2003). However, no alterations of the ambient sediment properties or decreases in diversity were recorded in our study. Neither colonisation nor physical alteration of the sediments, both of which can be lengthy processes, were needed for the community to recover to its pre-impacted state.

An increase in the number of taxa at Sites RA and RD occurred in response to the highest level of rainfall recorded at Orewa estuary in the month prior to sampling ( $275 \mathrm{~mm}$, Fig. 5). Of the 16 taxa highly correlated with the gradient in rainfall, 12 showed a pattern of high abundances at the highest level of rainfall recorded. The taxa that increased in response to rainfall (Anthopleura spp. Aonides sp., Cominella glandiformis, copepods, Diloma subostratum, Prionospio complex, nemerteans, Notaoacmea sp., Heteromastus sp., Nucula hartvigiana, Parakalliope spp., and Phoxocephalid sp.) cover a broad taxonomic range, including cnidarians, molluscs, polychaetes, crustaceans and nemerteans. These transient increases in density were likely the result of these organisms being transported from upstream sites, where they are more numerous (Ford \& Anderson 2005), after being eroded along with sediments from the bed, due to heavy rainfall. Previous studies indicate transportation of post-larvae associated with bedload movement on sandflats (Emmerson \& Grant 1991, Commito et al. 1995). One possible 
exception to this proposed mechanism of movement is the predatory snail Cominella glandiformis, which is relatively mobile over scales of metres to $10 \mathrm{~s}$ of metres, and may have moved to these sites in response to an increased availability of prey. The subsequent decline in diversity at the following sampling time ( $45 \mathrm{~d}$ later), suggests that either mortality or movement of transported organisms occurred reasonably quickly after the detected disruption from the rainfall event.

The densities of some motile crustaceans (Cirolana sp., isopods and Waitangi sp.) and insects were most variable at intermediate levels of rainfall (100 to $200 \mathrm{~mm} \mathrm{mo}^{-1}$ ), and were lowest at higher levels of rainfall. Sites RA and RD are both relatively sandy (averaging 56 to $57 \%$ fine sand) and are near the estuary mouth, where high current flow could be expected. It is possible that at times of high rainfall, flow rates in these habitats were sufficiently high to flush these small infauna (or the algal accumulations these detritivores may be associated with) away from these habitats, or to cause them to actively migrate away from this site. Cirolanid isopods are known to move with water flow (Yannicelli et al. 2002) and many amphipods and isopods found in the sediments are associated with detritus in hydrodynamically active environments (Marsden 1991). Some mobile sedimentdwelling crustaceans are known to have hydrodynamic limits above which they act as passive particles (Ford and Paterson 2001), and the densities of insects have also been found to change in response to flow in estuaries (Nance 1985).

Although rainfall was significantly correlated with changes in biological communities, there was no significant relationship between rainfall and many of the environmental variables measured at these sites. No clear changes were detected in ambient sediment composition or in bed height that may have triggered these biological changes. This does not, however, rule out the proposed mechanism of bedload transport of organisms to these sites. Limited evidence from sediment traps indicates that greater proportions of fine sediments in the water column may well have occurred after periods of heavy rain, compared to other times. Although there is no evidence that these finer sediments settled or remained at the sites, the greater proportions of fine sediments do suggest some movement of fine sediments from muddier upper reaches of the estuary with heavy rainfall. Currents, waves, the amount of freshwater input and the position in the estuary can all influence the extent of sediment deposition (Bell et al. 2000). Any of these factors may keep fine sediments entrained, but not necessarily the fauna, which may have greater weight (particularly the molluscs), or behavioural strategies inducing settlement. Behavioural strategies that promote post- settlement movement at rates different from that of passive particles have been documented from a number of taxa across a broad taxonomic range (Hooker 1995, Whitlatch et al. 1998, Ford \& Paterson 2001).

In this study, effects of rainfall were limited to a few isolated sites and were short-lived, identified as only a transitory increase in the number of taxa. These results contrast with other studies, where decreases in diversity occurred as a result of storms, or in experiments mimicking sedimentation from heavy rainfall (Hoese 1960, Peterson 1985, Tettelbach et al. 1985, Norkko et al. 2002, Lohrer et al. 2004). Transient increases or decreases in densities of taxa may happen naturally at lower levels of rainfall that occur more frequently in these systems, and from which recovery is fairly rapid. These results do not exclude potential sub-lethal effects of rainfall. The community structure at these estuaries is, however, diverse compared to estuaries with historically high sedimentation. Thus, chronic sub-lethal effects from rainfall that may mask acute effects are considered unlikely (Ford \& Anderson 2005).

This study has provided an important baseline of information regarding subtle responses and variability of macrofaunal assemblage structure in response to natural rainfall events. We consider this monitoring programme to be truly unique by virtue of inclusion of a seasonally stratified, yet explicitly climate-driven sampling design. Any changes in diversity detected after development of any of the monitored catchments in response to similar levels of rainfall should be easily detected and be clearly attributable to urban development activities. These results reinforce the temporally variable and unpredictable responses of biological assemblages to disturbance (Nichols \& Thompson 1985, Turner et al. 1995), highlighting the need for long-term monitoring studies to place larger-scale disturbances into an appropriate temporal context, especially by reference to subtler small-scale and short-term climate-induced disturbances. Monitoring relevant physical variables (such as rainfall, bedheight movement and sediment inputs) alongside biotic assemblages will allow environmental impacts of land-use changes and their potential interaction with changes in climate to be modelled and tested against known historical variation.

Acknowledgements. The data for this study forms part of an ongoing monitoring program funded by the Auckland Regional Council (ARC). Special thanks go to C. Hatton, B. Thompson and D. McCarthy at the ARC for their ongoing support of this research. We thank the many people at the University of Auckland's Leigh Marine Laboratory who contributed to the success of this project, including collection and processing of samples. Our thanks go especially to the contract staff (C. Bedford, W. Blom, P. Brown, B. Davison, 
A. Duncan, D. Feary, R. Ghosh, N. Harwood, C. Honeywill, L. Peacock and C. Williams) and the general staff at the laboratory (M. Birch, B. Doak, A. Cozens, B. Dobson, V. Stamp and T. Wustenberg). We also thank the 2 anonymous reviewers who improved this manuscript through their input.

\section{LITERATURE CITED}

Airoldi L (2003) The effects of sedimentation on rocky coast assemblages. Oceanogr Mar Biol Annu Rev 41:161-236

Anderson MJ (2001) A new method for non-parametric multivariate analysis of variance. Austral Ecol 26:32-46

Anderson MJ, ter Braak CJF (2003) Permutation tests for multi-factorial analysis of variance. J Stat Comp Sim 73: 85-113

Anderson MJ, Willis TJ (2003) Canonical analysis of principal coordinates: a useful method of constrained ordination for ecology. Ecology 84:511-525

Anderson MJ, Ford RB, Feary DA, Honeywill C (2004) Quantitative measures of sedimentation in an estuarine system and its relationship with intertidal soft-sediment fauna. Mar Ecol Prog Ser 272:33-48

Bell R, Green M, Hume TM, Gorman R (2000) What regulates sedimentation in estuaries. Water Atmos 8:13-16

Clarke KR, Gorley RN (2006) PRIMER v6: User Manual/Tutorial. PRIMER-E: Plymouth

Commito JA, Thrush SF, Pridmore RD, Hewitt JE, Cummings VJ (1995) Dispersal dynamics in a wind-driven benthic system. Limnol Oceanogr 40:1513-1518

Dobbs FC, Vozarik JM (1983) Immediate effects of a storm on coastal infauna. Mar Ecol Prog Ser 11:273-279

Dyer KR (1986) Coastal and estuarine sediment dynamics, Vol A. Wiley-Interscience, Chichester, NY

Emmerson CW, Grant J (1991) The control of soft-shell clam (Mya arenaria) recruitment on intertidal sandflats by bedload sediment transport. Limnol Oceanogr 36:1288-1300

Ford RB, Anderson MJ (2005). Ecological monitoring of the Okura and Whitford estuaries 2004-2005: temporal and spatial extensions of regional models. Auckland UniServices Report for Auckland Regional Council

Ford RB, Paterson DM (2001) Behaviour of Corophium volutator in still versus flowing water. Estuar Coast Shelf Sci 52: $357-362$

GESAMP (Joint Group of Experts on the Scientific Aspects of Marine Pollution) (1990) The state of the environment. Blackwell Scientific Publications, Oxford

Griffiths GA (1981) Some suspended sediment yields from South Island catchments, New Zealand. Water Res Bull 17: 662-671

Griffiths GA, Glasby GP (1985) Input of river-derived sediments to the New Zealand continental shelf: I. Mass. Estuar Coast Shelf Sci 21:773-787

Hall SJ (1994) Physical disturbance and marine benthic communities: life in unconsolidated sediments. Oceanogr Mar Biol Ann Rev 32:179-239

Hessell J (1988) The climate and weather of the Auckland region. Misc. Publ. 115 (20), New Zealand Meteorological Service, Wellington

Hewitt JE, Cummings VJ, Ellis JI, Funnell G, Norkko A, Talley TS, Thrush SF (2003) The role of waves in the colonisation of terrestrial sediments deposited in the marine environment. J Exp Mar Biol Ecol 290:19-47

Hicks DM (1990) Suspended sediment yields from pasture and exotic forest basins. In: Proc NZ Hydrol Symp, Taupo, p 1-4
Hoese HD (1960) Biotic changes in a bay associated with the end of a drought. Limnol Oceanogr 5:326-336

Hooker SH (1995) Preliminary evidence for post-settlement movement of juvenile and adult pipi, Paphies australis (Gmelin, 1790) (Bivalvia: Mesodesmatidae). Mar Freshw Behav Physiol 27:37-47

Kennish MJ (2002) Environmental threats and environmental future of estuaries. Environ Conserv 29:78-107

Lohrer AM, Thrush SF, Gibbs MM (2004) Bioturbators enhance ecosystem function through complex biogeochemical interactions. Nature 431:1092-1095

Manly BFJ (1997) Randomization, bootstrap and Monte Carlo methods in biology, 2nd edn. Chapman \& Hall, London

Manly BFJ, McAlevey L, Stevens D (1986) A randomization procedure for comparing group means on multiple measurements. Br J Math Stat Psych 39:183-189

Marsden ID (1991) Kelp-sandhopper interactions on a sand beach in New Zealand. I. Drift composition and distribution. J Exp Mar Biol Ecol 152:61-74

McArdle BH, Anderson MJ (2001) Fitting multivariate models to community data: a comment on distance-based redundancy analysis. Ecology 82:290-297

Nance JM (1984) The seasonal distribution of macrobenthos and sediments chronically impacted by oil/gas field produced water. PhD thesis, Texas A \& M University, College Station, TX

Nichols FH, Thompson JK (1985) Time scales of change in the San Francisco Bay benthos. Hydrobiologia 129:121-138

Norkko A, Thrush SF, Hewitt JE, Cummings VJ and 5 others (2002) Smothering of estuarine sandflats by terrigenous clay: the role of wind-wave disturbance and bioturbation in site-dependent macrofaunal recovery. Mar Ecol Prog Ser 234:23-41

Peterson CH (1985) Patterns of lagoonal bivalve mortality after heavy sedimentation and their paleoecological significance. Paleobiology 11:139-153

R Development Core Team (2005) R: A language and environment for statistical computing. R Foundation for Statistical Computing, Vienna, Austria

Tettelbach ST, Auster PJ, Rhodes EW, Widman JC (1985) A mass mortality of northern bay scallops, Argopecten irradians irradians, following a severe spring rainstorm. Veliger 27:381-385

Thrush SF, Whitlatch RB, Pridmore RD, Hewitt JE, Cummings VJ, Wilkinson MR (1996) Scale-dependant recolonization: the role of sediment stability in a dynamic sandflat habitat. Ecology 77:2472-2487

Turner SJ, Thrush SF, Pridmore RD, Hewitt JE, Cummings VJ, Maskery M (1995) Are soft-sediment communities stable? An example from a windy harbour. Mar Ecol Prog Ser 120:219-230

Westfall PH, Young SS (1993) Resampling-based multiple testing: examples and methods for p-value adjustment. Wiley, New York

Whetton P, Mullan AB, Pittock A (1996) Climate change scenarios for Australia and New Zealand. In: Bouma W, Pearman G, Manning M (eds) Greenhouse: coping with climate change. CSIRO Publishing, Collingwood, p 145-168

Whitlatch RB, Lohrer AM, Thrush SF, Pridmore RD, Hewitt JE, Cummings VJ, Zajac RN (1998) Scale-dependent benthic recolonization dynamics: life stage-based dispersal and demographic consequences. Hydrobiologia 376:217-226

Yannicelli B, Palacios R, Gimenez L (2002) Swimming ability and burrowing time of two cirolanid isopods from different levels of exposed sandy beaches. J Exp Mar Biol Ecol 273: $73-88$

Submitted: August 29, 2006; Accepted: November 13, 2006 Proofs received from author(s): May 16, 2007 